\title{
Principles for the selection and integration of educational multimedia materials
}

\author{
Tom Boyle \\ Department of Computing and Mathematics, Manchester Metropolitan University
}

This paper sets out to clarify the decision framework for the selection and integration of educational multimedia material into courses. Two main areas are discussed. The first involves matching the educational principles inherent in the multimedia artefact to the aims of the course. The opposition between instructionist and constructivist approaches is particularly highlighted. The second area concerns the models used to integrate the multimedia component into the overall course. The models are classified in terms of how they distribute the balance of responsibility for explicit educational structuring between the multimedia system and the course tutor. The paper does not set out prescriptive rules; it aims rather to inform and articulate the decision space for the tutor.

\section{Introduction}

A variety of educational multimedia resources, varying in both type and quality, is now available. The course tutor faces the problem of how to evaluate multimedia artefacts and integrate them into course delivery. This paper sets out a principled framework to guide and inform the choice. The task can be approached from two different directions. The first is technologically driven: we survey the latest developments in multimedia and telematics, and query how we can adapt educational practice. The second line of approach is driven by an educational vision: we establish educational goals and principles, and examine how the technology can help implement these goals. In the early multimedia era, developments have often been driven from the first direction. There has been an opportunistic rush to exploit the new technology which has often led to poor-quality systems. This paper follows the second line of approach. It starts with educational aims and principles and finishes with the technology. The paper develops in this way to emphasize the priority of the issues. In a real decision-making context, the issues have to be considered in parallel in order to match educational principles and technological possibilities.

The paper articulates the decision space for selecting and integrating multimedia materials in two areas:

- the educational principles that underpin the multimedia contribution - these may be viewed from weakly to strongly articulated, and in terms of the opposition between instructionist and constructivist pedagogies; 
- a model for the integration of multimedia materials based on decisions along a cline from the maximum flexibility of resource-based learning (Hall et al, 1995) to the maximum commitment of structured multimedia courseware (Laurillard, 1993).

\section{The educational vision - constructivist or instructionist?}

Traditionally, CAL has been strongly influenced by the transmission model of learning. The most systematic representation of this approach is Instructional Systems Design (ISD) (e.g. Price, 1991). It emphasizes a strong didactic approach to computer-based instruction. There is a clear structuring of the content to be learned, usually based on a systematic, hierarchical analysis of the knowledge in the target domain. There is often an emphasis on drill and practice, and individual progress is directed by the computer, based on the results of online tests. This approach has been strongly carried over into the multimedia domain by Integrated Learning Systems (ILSs), which have proved popular in many schools (Underwood et al, 1996). It often acts, at a weaker level, as the default model for many commercial systems and systems developed through educational grants such as TLTP (Teaching and Learning Technology Programme).

Constructivism proposes a radically different approach to devising computer-based interactive multimedia learning environments (IMLEs). Whereas instructional design has its roots in behaviourism, constructivism has its roots in the cognitive developmental theories of Vygotsky and Piaget. The primary theme of constructivism is that people construct their knowledge of the world through interaction. The focus switches from systematic teaching to supporting learning. The primary aim of a computer-based educational system is to engage the user in this constructive learning process. This emphasis has led to the development of a number of design principles for educational software. These include:

- the use of 'authentic' learning tasks so that the learning is seen as meaningful by the students;

- the use of discovery learning methods that enable the students to construct their own understanding, rather than instruction by a computer;

- an emphasis on learning how to learn and how to solve problems rather than learning facts;

- support for collaborative learning and problem-solving.

The constructivist principles are well expounded in two special issues of Educational Technology (May and September 1991), and in several papers, e.g. Cunningham et al (1993) and Grabinger and Dunlap (1995). These constructivist principles have become strong themes in a variety of modern educational multimedia systems, for example the KIE system (Linn, 1996), 'Model-It' (Jackson et al, 1996), and VR-based training (Cobb and Brown, 1997).

\section{Matching multimedia systems to the educational vision}

The first criterion for evaluating multimedia courseware is the nature of the educational model built into the IMLE. This may be strongly or weakly articulated. A weakly 
articulated model is most likely to reflect the older, default instructionist approach. A strongly articulated learning structure may reflect an instructionist or a constructivist approach. Constructivist approaches are more radical, but they have a firm base in psychological theory, and provide a coherent base for learner-centred learning. Tutors should be explicit about their educational aims and objectives. They can then make a principled choice about the type of multimedia educational systems to be used.

An important issue is how this educational approach fits in with the evaluation models used in the institution. Modern constructivist approaches are often focused on skills not easily measured by traditional examinations. The tutor needs to think about the relationship between the learning environment and the evaluation system. The implications of this reflection may suggest modifications to the evaluation system, for example with a greater emphasis on (group-based) coursework versus formal examinations.

This issue points to the central consideration: what is the driving educational vision? Is it to improve, or make more efficient, traditional forms of teaching? An alternative, more ambitious aim is to transform the learning experience to be more dynamic, active and learnercentred (e.g. Papert, 1980, 1993). The choice of IMLE will crucially be affected by, and reflect, the nature of the educational ambition of the tutors and the organization. A radical, learnercentred agenda would point strongly to the selection of constructivist systems.

\section{Models for integration and use}

The strategic educational vision has to be realized through a model for integration and use. This model links the educational goals to the concrete delivery context. The choices for the integration of multimedia materials and courseware may be represented on a cline. The choice points on this cline represent various trade-offs between the degree of explicit educational support of the multimedia component balanced against the degree of educational freedom left with the tutor. Three significant choice points may be identified on this cline: resource-based learning, educational tools and 'phenomenaria', and structured multimedia courseware. These represent significant alternatives for integrating multimedia resources or courseware.

\section{Resource-based learning}

Resource-based learning emphasizes providing learners with access, usually through networked computers, to a rich set of basic resources for learning. These resources may be provided on CD-ROMs (for example, electronic encyclopaedias and reference works), or increasingly through the World Wide Web. This approach emphasizes the re-use of materials generally available (for example, on the Web) and the building of electronic libraries providing access to educational source material.

Hall et al (1995) argue for the advantages of this approach. It is cost-effective because of the high degree of re-usability of materials. It provides maximum flexibility for the course tutor who may pick and choose the resources to suit a particular course. They also argue that it provides a natural transition for tutors from traditional modes of teaching. Education, they argue, has always been resource-based. It is, therefore, an easy transition for the tutor from using traditional resources such as books to using electronic resources such as documents and pictures on the Internet. This ease of transition, they argue, will 
make it easier to scale up learning technology to the stage where it makes a significant impact on the overall education system.

The central criticism of resource based learning is expressed most trenchantly by Laurillard (1993): '[ . . . ] beneath the rhetoric of 'giving students control over their learning' is a dereliction of duty. We never supposed students could do that with a 'real' library; why should they be able to do it with an electronic one?' (Laurillard, 1993, 206).

Resource-based learning seems to avoid the central educational issues of integration and use. It leaves responsibility for these issues where they have always been - with the individual tutor. Interlinked with this, strangely, is an emphasis on student-centred learning, where students take responsibility for their own learning. This balance has to be handled very carefully to avoid a form of educational dumping.

\section{Intermediate layers of educational support}

Intermediate levels of direct educational impact may be provided through the use of electronic tools and materials explicitly designed for educational use. There are a wide range of educational tools available, from general-purpose tools such as Logo (Papert, $1980,1993)$ to tools orientated to supporting particular learning tasks such as learning program design, for example 'Braque' (Boyle and Davies, 1996). These tools have been explicitly designed to support particular educational processes, such as discovery learning. Semi-structured levels of support are also provided by explicit educational 'phenomenaria' (Perkins, 1991) such as simulations and microworlds. These vary from supporting open exploration to specific goal-directed learning tasks. 'Dans le quartier St. Gervais', for example, permits virtual visits to a district in Paris (Hodges and Sasnett, 1993). 'Murder One' is at the other end of the simulation spectrum (Gibbens, 1992); here law students play the role of preparing and presenting a court case.

The educational advantages of these systems are compelling. They provide powerful sources for experiential learning, either through constructing entities with a tool, or working through the simulation. They have a clear, intrinsic educational focus, and they can be very attractive and motivating. They provide a natural means of implementing constructivist approaches to learning. The balancing constraints are that they are more demanding in terms of delivery resources and in course restructuring. They require careful thought about curriculum and pedagogy, and they may require a significant transformation in course delivery.

\section{Structured courseware}

The highest level of direct educational impact is provided by structured, multimedia courseware. Traditional ISD-based systems usually provided structured courseware. This has led some critics to identify structured courseware with the older approach to learning technology. However, there is no necessary linkage. Extensive structured courseware can equally be developed within the constructivist tradition. The CLEM system, for example, covers the first-year curriculum for learning to program in Modula-2 (Boyle and Davies, 1996; Boyle, 1997). This provides over 50 hours of CAL. The pedagogy used, however, is radically constructivist. It uses a 'guided discovery' learning approach where students learn through examples, feedback, and the active construction of the rules of the language. 
The advantages of structured courseware arise from the direct commitment to an explicit curriculum and pedagogy. The key educational issues are directly addressed in the design of these systems. In terms of direct educational impact, they are at the opposite end of the spectrum to resource-based learning. They have, potentially, a marked impact on the efficiency with which education can be delivered. The tutor is freed from information transmission to deal with other issues. The tutor may become more of a learning manager and coach than a lecturer.

The main disadvantage is the potential lack of flexibility. Local tutors may not wish a whole course to be replaced. If it is, they usually want to tailor and modify the materials. Structured courseware systems do not always support this local modification, and the mechanisms for maintaining coherent local changes are not fully clear.

\section{Summary}

The selection of appropriate multimedia materials depends on the educational vision of tutors and managers. This vision may vary from incremental improvement to a radical transformation of teaching and learning. Constructivist educational materials provide support for the more radical transition from a teacher-centred to a learner-centred approach.

This transition may involve one or more delivery and integration options. Resource-based learning supports re-use of widely available materials, and can easily be used to extend or modify existing modes of teaching. Educational tools and simulations provide a more direct impact on practice which requires greater adaptation by tutors and educational organizations. Structured courseware often demands a major shift from teacher-centred to learner-centred educational practice. These three modes of integration and use are not mutually exclusive. They represent options for integrating multimedia materials which have different impact implications. The choice for a specific situation may involve a judicious mix of the different options.

\section{References}

Boyle, T. (1997), Design for Multimedia Learning, London: Prentice Hall.

Boyle, T. and Davies, M. (1996), 'Hypermedia environments for learning to program' in Brusilovsky, P., Kommers, P. and Streitz, N. (eds), Multimedia, Hypermedia and Virtual Reality, LNCS 1077, Berlin: Springer.

Cobb, S. and Brown, D. (1997), 'The promotion of health and safety training at work using virtual factories', VRET '97, Virtual Reality in Education and Training, Loughborough, June 1997.

Cunningham, D. J., Duffy, T. M. and Knuth, R. (1993), 'The textbook of the future' in McKnight, C., Dillon A. and Richardson J. (eds), Hypertext: A Psychological Perspective, Chichester: Ellis Horwood.

Gibbons, H. (1992), 'Murder One - developing interactive simulations for teaching law', CTISS File, 14.

Grabinger, R. S. and Dunlap, J. C. (1995), 'Rich environments for active learning: a definition', $A L T-J 3$ (2), 5-34. 
Hall, W., Hutchings, G. and White, S. (1995), 'Breaking down the barriers: an architecture for developing and delivering resource based learning materials' in Tinsley, J. D. and van Weert, T. J. (eds), World Conference on Computers in Education VI: WCCE '95 Liberating the Learner, London: Chapman and Hall.

Hodges, M. E. and Sasnett, R. M. (1993), Multimedia Computing: Case Studies from MIT Project Athena, Reading MA: Addison-Wesley.

Jackson, S. L., Stratford, S. J., Krajcik, J. and Soloway, E. (1996), 'A learner-centred tool for students building models', Communications of the $A C M, 39$ (4), 48-9.

Laurillard, D. (1993), Rethinking University Teaching, London: Routledge.

Linn, M. C. (1996), 'Key to the information highway', Communications of the ACM, 39 (4), 34-5.

Papert, S. (1980), Mindstorms: Children, Computers and Powerful Ideas, New York: Basic Books.

Papert, S. (1993), The Children's Machine, New York: Basic Books.

Perkins, D. N. (1991), 'Technology meets constructivism: do they make a marriage?', Educational Technology, 31 (5), 18-23.

Price, R. V. (1991), Computer-Aided Instruction: A Guide for Authors, Pacific Grove, CA: Brooks/Cole.

Underwood, J., Cavendish, S., Dowling, S., Fogelman, K. and Lawson, T. (1996), 'Are integrated learning systems effective learning tools?', Computers in Education, 26 (1-3), $33-40$. 